\title{
G wie Grand Old Men oder die vergangene Gegenwart
}

\section{Dominik Heim}

«Denn die Menschen: Das sind ihre Geschichten. Geschichten aber muss man erzählen", sagt der deutsche Philosoph Odo Marquard [1]. Und Geschichten findet man mit graumelierten Haaren immer mehr. Wobei graumeliert eine euphemistische Beschönigung ist, die beim Cover von Leonard Cohens Alterswerk «popular problems» noch zutreffen mag, Georges Moustaki und der früh verstorbene Jon Lord von Deep Purple waren weiss.

Weiss hat mich auch gefesselt beim Umsteigen in Milano Centrale. Bekanntlich hat man dort (wegen der Verspätungen) immer etwas Zeit. Ein weisser Name auf rotem Grund, ein schmaler Eingang und dahinter dann eine lukullische Auswahl an Büchern und CDs mit vielen verlorenen Schätzen. Gerne hätte die Zeit etwas stehenbleiben können. Für eine alte Fabrizio de André «in concerto» von 1997/98 reichte es noch (der Cantautore starb 59-jährig im folgenden Jahr). Feltrinelli heisst der Laden und der Name erinnert: Giangiacomo Feltrinelli, der legendäre Verleger, der Dr. Schiwago von Boris Pasternak herausbrachte. Und ich schaue in Julie Christies wehmütige Augen im gleichnamigen Film von David Lean (1965). Feltrinelli, Freund von Che Guevara und Rudi Dutschke, ging Ende der 6oer Jahre in den Unter-

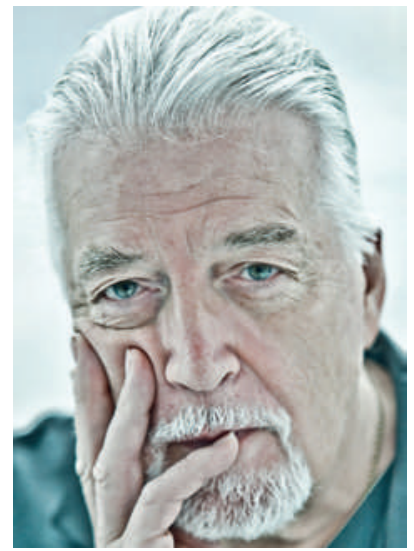

"He was a man who used to notice such things ... and now he is gone." Aus "Afterwards", Gedicht von Thomas Hardy, auf der CD "To notice such things" von Jon Lord. (Jon Lord photo-R.I.P.).
göwer-Donati, wir spalten das Ringband von de Quervain, wir mach(t)en das Kocher'sche Manöver beim Billroth I, und immer noch ist bei den Varizen der Schlauchtest Trendelenburg-positiv. Eine Galerie von Grand Old Men hängt an den Wänden der Hörsäle. Sie prägten das chirurgische Handwerk ihrer Zeit - und auch heute noch. Sie geleiteten ganze Generationen durch ihre Ausbildung, und ihre Ansichten wurden zu Dogmen. Aber «Dogmen sind die Häresie von morgen", schrieb Jaspers, und deshalb werden sie dann doch einmal vom Sockel gestossen. Lenin riss man beim Mauerfall herunter und seine Unterschrift von 1916 im Gästebuch des Hotels Bären im Kiental heraus, die Vagotomie wurde ein Opfer des Helicobacters, die anatomische Reposition der Frakturfragmente wich der Überbrückung. Jede Zeit hat(te) ihre Götter, vom Olymp aus führten sie die gewöhnlichen Sterblichen. In der Chirurgie begleite(te)n sie uns in den Operationssaal. In der Musik sind sie «Digitally remastered» und überdauern die musikalische und im Operationssaal die chirurgische Coverversion. The Final Cut nannten Pink Floyd ihr letztes Album. Auf Final folgt jetzt (ohne Roger Waters) The Endless River, gewisse $\mathrm{Mu}$ sik bleibt halt wie Mythen "endlos" und zeitlos, denn sie ist "louder than grund, gründete die linksradikale Zelle «Gruppo d'azione partigiana» in Mailand und wurde 1972 bei einem Sprengstoffanschlag auf einen Hochleitungsmast selbst getötet. Die "Brigate rosse» wurden damals gegründet, Aldo Moro wurde später ermordet. Angst und Aufruhr herrschte im Süden, im Norden auch, es war eine Zeit politischer Wirren und Irrungen in Europa, man warf Pflastersteine und löschte Züri brennt mit Wasserwerfern und Tränengas [2]. Nicht nur das «Make love not war»-Woodstock, auch der linksradikale Terror hinterliessen Spuren.

Spuren hinterliessen auch sie, wenn auch ganz andere: Die Grand Old Men der Chirurgie. Ihre Technik(en) wenden wir immer noch an: Die Hautnaht nach All- words»! Diese Geschichten und Mythen begleiten uns und tragen zum Verständnis der Gegenwart bei, sei es Feltrinelli in Mailand oder Allgöwer in der Chirurgie. Aber «... Geschichten muss man erzählen. Das tun die Geisteswissenschaften: Sie kompensieren Modernisierungsschäden, indem sie erzählen; und je mehr versachlicht wird, desto mehr - kompensatorisch - muss erzählt werden: Sonst sterben die Menschen an narrativer Atrophie» [1]. Von Atrophie war hier keine Rede!

1 Odo Marquard. Eröffnungsvortrag der Jahresversammlung der Westdeutschen Rektorenkonferenz. Bamberg, 5. Mai 1985.

2 Züri brennt, Video/ DVD 1981. Videoladen Zürich, über die Jugendunruhen der achtziger Jahre. 